\title{
Simple Hysterectomy for Patients with Stage IA2 Cervical Cancer: A Retrospective Cohort Study
}

\author{
Qing Liu' \\ Yu Xu iD ${ }^{2-4}$ \\ Yuedong $\mathrm{He}^{2,3}$ \\ Yi Du ${ }^{2,3}$ \\ Qianwen Zhang ${ }^{2}$ \\ Ya Jia ${ }^{2}$ \\ Ai Zheng ${ }^{2}$ \\ 'School of Medical and Life Science, \\ Reproductive \& Women-Children \\ Hospital, Chengdu University of \\ Traditional Chinese Medicine, Chengdu, \\ People's Republic of China; ${ }^{2}$ Department \\ of Obstetrics and Gynecology, West China \\ Second University Hospital, Sichuan \\ University, Chengdu, People's Republic of \\ China; ${ }^{3}$ Key Laboratory of Birth Defects \\ and Related Diseases of Women and \\ Children (Ministry of Education), Sichuan \\ University, Chengdu, People's Republic of \\ China; ${ }^{4}$ West China Medical Center, \\ Sichuan University, Chengdu, People's \\ Republic of China
}

Correspondence: $\mathrm{Yu} \mathrm{Xu}$

Department of Obstetrics and Gynaecology, West China Second University Hospital, Sichuan University, Chengdu, People's Republic of China

Email xuyu_md_wc@outlook.com
Objective: The purpose of this study was to compare long-term survival outcomes of simple hysterectomy versus radical hysterectomy in stage IA2 cervical cancer.

Methods: A total of 440 patients who underwent simple hysterectomy (SH group) or radical hysterectomy (RH group) between 2014 and 2019 were included in this study. Overall survival (OS) and disease-free survival (DFS) were analyzed using the Kaplan-Meier method and compared by the Log rank test. The Cox proportional hazards regression model was employed to control for confounders.

Results: There were 258 patients in the RH group and 182 patients in the $\mathrm{SH}$ group. The two groups had similar 5-year DFS rate $(89.25 \%$ vs $91.14 \%, P=0.562)$ and 5 -year OS rate (95.71\% vs $94.76 \%, P=0.482$ ). Multivariable analysis showed that simple hysterectomy was not independently associated with poorer DFS (aHR, 1.608; 95\% CI, 0.640-4.041; $P=0.312$ ) and OS (aHR, 1.122; 95\% CI, 0.319-3.493; $P=0.858$ ) than radical hysterectomy for women with stage IA2 cervical cancer.

Conclusion: For stage IA2 cervical cancer, a simple hysterectomy is safe and effective. Further studies are needed to testify against our findings.

Keywords: cervical cancer, stage IA2, simple hysterectomy, overall survival, disease-free survival

\section{Introduction}

Cervical cancer is one of the most common female malignancies, which seriously threatens women's health and represents a major global health challenge. ${ }^{1,2}$ The incidence and associated mortality of cervical cancer in developed countries has fallen sharply over the past decades. ${ }^{3}$ Unfortunately, in underdeveloped countries, a large number of women die of cervical cancer every year because of a lack of organized screening and human papillomavirus (HPV) vaccination programs. ${ }^{1,3,4}$

For patients with early-stage cancer of the cervix, surgery including radical hysterectomy and pelvic lymphadenectomy is the standard protocol of management. ${ }^{5}$ The majority of early-stage cervical cancer can be cured by radical hysterectomy, with a favorable 5-year overall survival rate of up to $90 \%{ }^{3}$ However, these procedures are associated with significant postoperative morbidities, which consist of bowel dysfunctions and ureteral fistula formation, and have adverse effects on the quality of life in patients. $^{6-10}$ These morbidities are considered to be related to the removal of the parametrial tissues adjacent to the cervix, which carry autonomic nerve fibers innervating gastrointestinal and genitourinary activities. ${ }^{11-13}$

Many studies have shown that the risk of parametrial metastases in select patients with early-stage cervical cancer is fairly low. Patients with a small volume 
of tumor, without lymphovascular space invasion (LVSI) and regional lymph node involvement, have been thought to have less than $1 \%$ possibility of parametrial invasion, ${ }^{14-16}$ indicating that perhaps those patients could have been overtreated with radical hysterectomy. Also, several studies have demonstrated that simple trachelectomy plus pelvic lymphadenectomy is safe and feasible for low-risk early-stage cervical cancer patients who desire future fertility. ${ }^{17-19}$ All these data have justified the hypothesis that less radical surgery may be feasible for selecting patients with early-stage cervical cancer. Thus, we performed this retrospective cohort study to explore the long-term oncological outcomes of simple hysterectomy for women with the 2009 International Federation of Gynecology and Obstetrics (FIGO) stage IA2 cervical cancer.

\section{Materials and Methods}

\section{Data Source}

This study was a single institution, retrospective, observational study, and the data used in this study were originated from the West China Second University Hospital, Sichuan University (WCSUH-SCU), the largest teaching women's and children's hospital in southwest China. This study was approved by the Institutional Review Board of WCSUH-SCU, written informed consent was waived because this study was a retrospective observational study, and this study did not involve any identifiable private information. The study was carried out following the Declaration of Helsinki. ${ }^{20}$

Clinicopathological data were extracted from patient files and the medical record management system at WCSUH-SCU. The collected data were as follows: age of the patient at diagnosis, marital status at diagnosis, preoperative American Society of Anesthesiology (ASA) physical status score, histological type, grade of tumor differentiation, the status of lymph-vascular space invasion (LVSI), information on surgery (radical hysterectomy or simple hysterectomy, laparoscopic hysterectomy or open hysterectomy, with or without pelvic lymphadenectomy), whether underwent postoperative adjuvant chemotherapy or radiotherapy. At WCSUH-SCU, after completing initial treatment, patients with cervical cancer underwent a postoperative follow-up visit every four months within the first two years, every six months in the third year, and once a year thereafter. At each follow-up visit, the patient at least underwent pelvic examination, cytology, and pelvic ultrasound. Pelvic magnetic resonance imaging or computed tomography was performed every six months to identify disease recurrence. If necessary, a positron emission tomography/computed tomography (PET/CT) or a biopsy was performed to identify the recurrence of the disease.

All follow-up procedures of this study were conducted using the return visit system and outpatient medical record system of WCSUH-SCU or by telephone call. We collected the data including vital status, time of recurrence, and time of death.

\section{Inclusion and Exclusion Criteria}

Patients who met the following criteria were included in this study: (1) with primary cervical cancer who were treated and followed up at WCSUH-SCU between January 2014 and December 2019, (2) with a disease of stage IA2 according to the FIGO 2009 staging system, (3) underwent simple hysterectomy or radical hysterectomy, (4) did not undergo neoadjuvant treatment, and (5) no evidence of regional lymph node enlargement by preoperative imaging.

The exclusion criteria were as follows: (1) pregnant women who were diagnosed with cervical cancer, (2) lost to follow-up, (3) had a history of another tumor, or (4) neoplasm of the cervical stump.

\section{Outcomes of Interest}

The outcomes of interest in this study were 5-year overall survival (OS) rate and 5-year disease-free survival (DFS) rate. OS was calculated as the number of months from the start of treatment for cervical cancer to death from any cause. DFS was defined as the time from the surgery for cervical cancer to the date of disease recurrence or death from any cause. Patients were followed up until died or December 31, 2020. Data regarding patients with no evidence of recurrence or death were censored at the date of the last follow-up.

\section{Statistical Methods}

Patients were divided into two groups based on the type of hysterectomy (simple hysterectomy or radical hysterectomy), and comparisons were made between these two groups. Categorical variables were compared with the chisquared test, and continuous variables were performed using the Student's $t$-test. 5-year DFS rate and 5-year OS were estimated using the Kaplan-Meier method, and differences were compared using the Log rank test. The Cox 
proportional hazards regression analyses were applied for univariate and multivariate analyses and to calculate the hazard ratios $(\mathrm{HR})$, adjusted $\mathrm{HR}$, and 95\% confidence interval (CI) of each variate. Variables with $P<0.2$ in the univariable analyses were included in the multivariable analyses. A two-sided $P$-value of less than 0.05 was considered statistically significant.

Statistical analyses in this study were performed using STATA (v15; STATA, College Station, TX; Computing Resource Center, Santa Monica, CA).

\section{Results}

\section{Patients Characteristics}

The flow chart of patient selection is shown in Figure 1. During the study period, 4631 patients with cervical cancer were treated at WCSUH-SCU. After excluding cases that did not meet the inclusion criteria, 440 patients with stage IA2 cervical cancer were finally included in this study. Of these included patients, 258 patients underwent radical hysterectomy, and the rest received simple hysterectomy as initial treatment. Among patients who underwent a radical hysterectomy, $159(61.6 \%)$ patients received minimally invasive surgery; within the simple hysterectomy cohort, the proportion was $131(72 \%)$.

The clinicopathologic characteristics of these patients are presented in Table 1. Based on the type of hysterectomy, the included patients have been divided into two groups, namely the radical hysterectomy group (RH group) and the simple hysterectomy group (SH group). No significant differences emerged in the clinicopathologic variables between these two groups, except for the follow-up duration $(P<0.001)$, surgical route $(P=0.025)$, postoperative adjuvant chemotherapy $(P<0.001)$, and adjuvant radiotherapy $(P<0.001)$.

\section{Survival Outcomes}

The median duration of the follow-up was 45 months (range, 1-83 months) in the RH group and 39 months (range, 1-80 months) in the SH group. During follow-up, six cases $(2.33 \%)$ of cervical cancer recurrence were observed in the RH group and five patients $(2.75 \%)$ had cervical cancer recurrence in the $\mathrm{SH}$ group, there was no statistical difference in the risk of cancer recurrence between the $\mathrm{RH}$ group and the $\mathrm{SH}$ group $(P=0.49)$. All recurrence cases were local recurrence. The most
4631 women with cervical cancer

treated at our hospital between

2014 and 2019 were identified

\section{1 women underwent hysterectomy}

\section{3 women had disease of stage IA2}

440 women were included, others

were excluded based on the

following reasons:

a. lost to follow-up ( $n=93)$,

b. were pregnant $(n=26)$,

c. had a history of other tumor $(n=18)$.

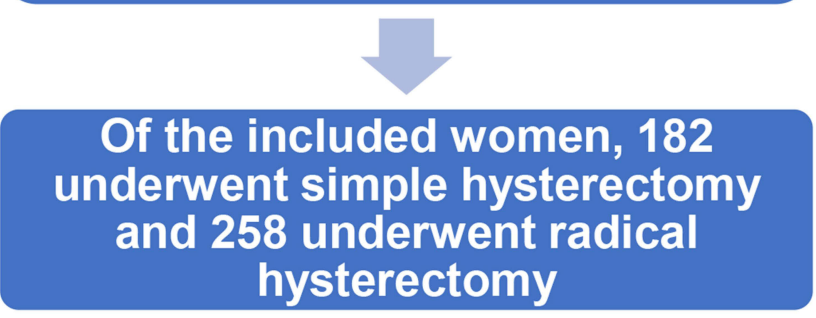

Figure I Flow chart of patient selection.

common site of disease recurrence was the intrapelvic region $(41.7 \%)$, followed by vaginal stump (33.3\%) and pelvic lymph nodes $(25 \%)$. The site profiles of disease recurrence between the $\mathrm{RH}$ group and the $\mathrm{SH}$ group were similar.

The 5-year DFS rate by the Kaplan-Meier method was $89.25 \%(95 \% \mathrm{CI}, 82.90-93.34 \%)$ in the $\mathrm{RH}$ group and $91.14 \%$ (95\% CI, 81.51-95.88\%) in the SH group. For stage IA2 cervical cancer, noninferiority of simple hysterectomy to radical hysterectomy in 5-year OS was observed (SH vs RH, HR: 1.298, 95\% CI, 0.537-3.137, $P=0.562$ ). 
Table I Clinical and Pathological Characteristics of the Study Population

\begin{tabular}{|c|c|c|c|}
\hline & Radical Hysterectomy $(\mathrm{N}=258)$ & Simple Hysterectomy $(\mathrm{N}=\mid \mathbf{8 2})$ & $\mathbf{P}$ \\
\hline $\begin{array}{l}\text { Age at diagnosis } \\
\text { Mean }\left(S D^{a}\right)\end{array}$ & $44.3(12.3)$ & 44.5 (12.8) & 0.848 \\
\hline $\begin{array}{l}\text { Marital status } \\
\text { Married } \\
\text { Single } \\
\text { Unknown }\end{array}$ & $\begin{array}{c}17 \mid(66.3 \%) \\
69(26.7 \%) \\
18(7.0 \%)\end{array}$ & $\begin{array}{c}\text { II } 4(62.6 \%) \\
60(33.0 \%) \\
8(4.4 \%)\end{array}$ & 0.25 \\
\hline $\begin{array}{l}\text { Duration of follow up } \\
\text { Median (Min, Max) }\end{array}$ & $45.0(1.00,83.0)$ & $39.0(1.00,80.0)$ & $<0.001$ \\
\hline $\begin{array}{l}\text { ASA }^{\mathbf{b}} \text { score } \\
\text { I/II } \\
\text { III }\end{array}$ & $\begin{array}{c}228 \text { (88.4\%) } \\
30(11.6 \%)\end{array}$ & $\begin{array}{c}164(90.1 \%) \\
18(9.9 \%)\end{array}$ & 0.856 \\
\hline $\begin{array}{l}\text { Histology } \\
\text { Squamous cell carcinoma } \\
\text { Adenocarcinoma } \\
\text { Adenosquamous carcinoma }\end{array}$ & $\begin{array}{l}173(67.1 \%) \\
59(22.9 \%) \\
26(10.1 \%)\end{array}$ & $\begin{array}{l}\text { II } 6(63.7 \%) \\
45(24.7 \%) \\
21(11.5 \%)\end{array}$ & 0.759 \\
\hline $\begin{array}{l}\text { Grade } \\
\text { Grade I/II } \\
\text { Grade III }\end{array}$ & $\begin{array}{c}207(80.2 \%) \\
51(19.8 \%)\end{array}$ & $\begin{array}{c}143(78.6 \%) \\
39(21.4 \%)\end{array}$ & 0.719 \\
\hline $\begin{array}{r}\text { LVSI }^{\mathbf{c}} \\
\text { No } \\
\text { Yes }\end{array}$ & $\begin{array}{c}221(85.7 \%) \\
37(14.3 \%)\end{array}$ & $\begin{array}{c}152(83.5 \%) \\
30(16.5 \%)\end{array}$ & 0.591 \\
\hline $\begin{array}{l}\text { Parametrial involvement } \\
\text { No } \\
\text { Yes }\end{array}$ & $\begin{array}{c}255(98.8 \%) \\
3(1.2 \%)\end{array}$ & $\begin{array}{l}\text { Not applicable } \\
\text { Not applicable }\end{array}$ & NA \\
\hline $\begin{array}{l}\text { Route of surgery } \\
\text { Laparoscopy } \\
\text { Laparotomy }\end{array}$ & $\begin{array}{l}159(61.6 \%) \\
99(38.4 \%)\end{array}$ & $\begin{array}{c}|3|(72.0 \%) \\
5 \mid(28.0 \%)\end{array}$ & 0.025 \\
\hline $\begin{array}{l}\text { Pelvic lymphadenectomy } \\
\text { No } \\
\text { Yes }\end{array}$ & $\begin{array}{c}37(14.3 \%) \\
221(85.7 \%)\end{array}$ & $\begin{array}{c}33(18.1 \%) \\
149(81.9 \%)\end{array}$ & 0.293 \\
\hline $\begin{array}{l}\text { Adjuvant radiotherapy } \\
\text { No } \\
\text { Yes }\end{array}$ & $\begin{array}{c}248(96.1 \%) \\
10(3.9 \%)\end{array}$ & $\begin{array}{l}16 \mid(88.5 \%) \\
21(11.5 \%)\end{array}$ & $<0.001$ \\
\hline $\begin{array}{l}\text { Adjuvant chemotherapy } \\
\text { No } \\
\text { Yes }\end{array}$ & $\begin{array}{c}245(95.0 \%) \\
13(5.0 \%)\end{array}$ & $\begin{array}{l}\text { I55 (85.2\%) } \\
27(14.8 \%)\end{array}$ & $<0.001$ \\
\hline
\end{tabular}

Notes: a Standard deviation; ${ }^{b}$ American Society of Anesthesiology; ${ }^{\mathrm{C}}$ lymph-vascular space invasion.

The 5-year OS rate was $95.71 \%$ (95\% CI, 90.35-98.12\%) in the RH group and $94.76 \%(95 \% \mathrm{CI}, 84.70-97.87 \%)$ in the SH group. There was no statistical difference in OS between the two groups ( $\mathrm{SH}$ vs RH, HR: $1.522,95 \% \mathrm{CI}$ $0.472-4.915, P=0.482$ ). Figure $2 \mathrm{~A}$ and $\mathrm{B}$ show the Kaplan-Meier curves for DFS and OS in the study cohorts, respectively.

\section{The Cox Proportional Hazards Regression} Model

To study the feasibility and safety of simple hysterectomy for patients with stage IA2 cervical cancer after controlling for the potential confounding factors, the Cox proportional hazards regression model was employed. Based on the results of univariate analysis (Table 2), variables 


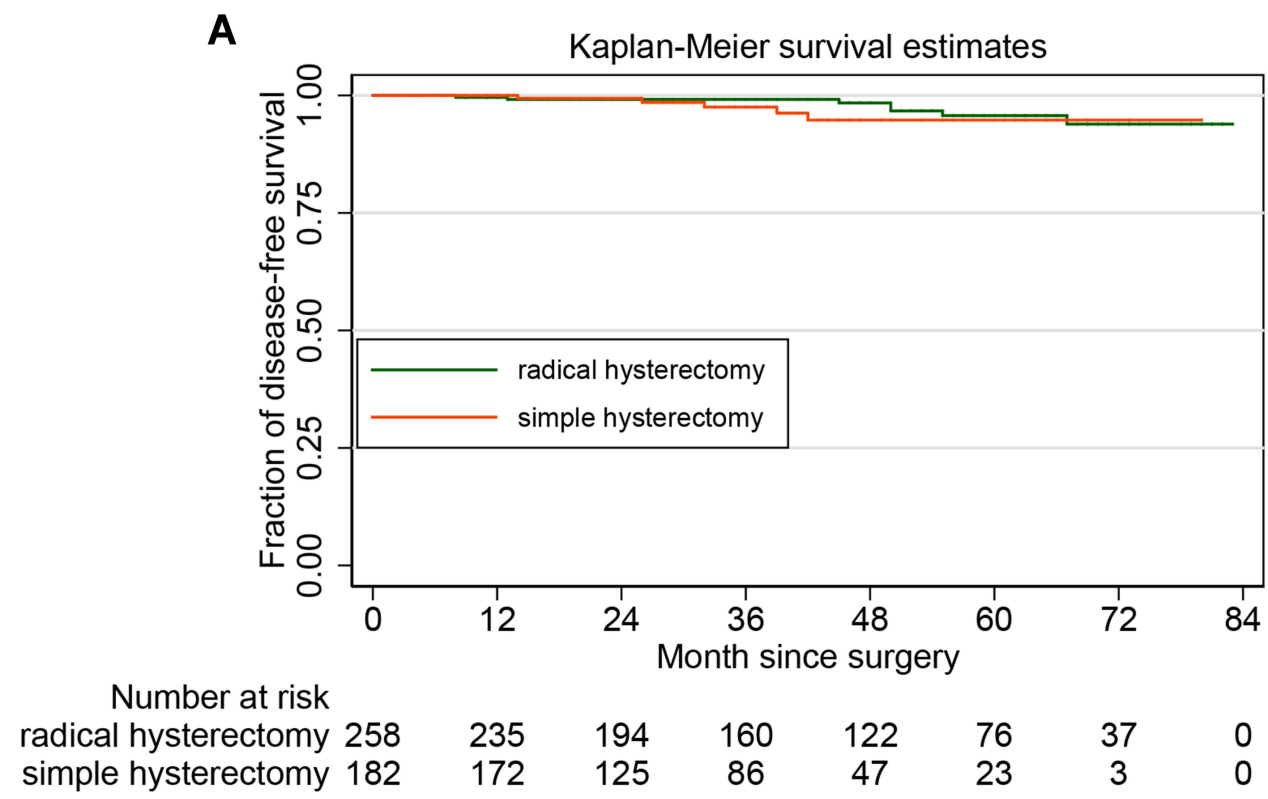

B

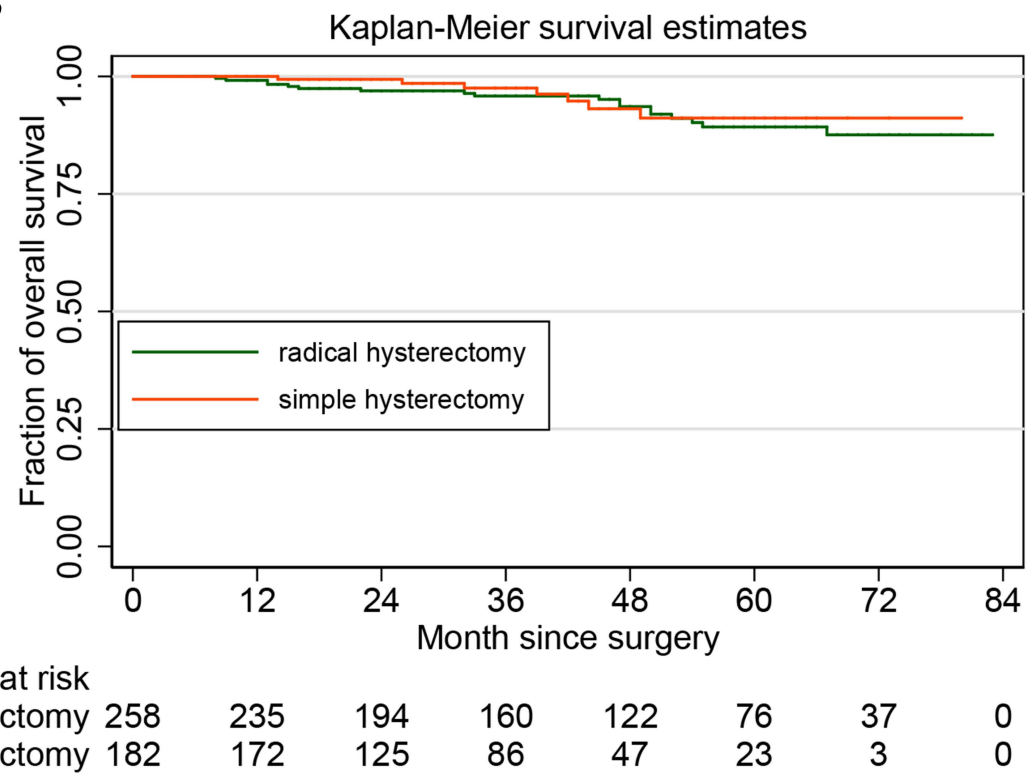

Figure 2 Survival analysis: (A) for disease-free survival and (B) for overall survival.

that with a $P$ value of less than 0.2 were included in the Cox proportional hazards regression model, as follows: age at diagnosis, marital status at diagnosis, preoperative ASA physical status score, grade of tumor differentiation, LVSI, and adjuvant radiotherapy. The results of the Cox proportional hazards regression analysis indicated that the type of hysterectomy was not independently associated with the long-term survival of the patients with stage IA2 cervical cancer (DFS. aHR, 1.608. 95\% CI, 0.640-4.041. $P=0.312$; OS. aHR, 1.122. $95 \%$ CI, 0.319 3.493. $P=0.858)$.
Moreover, the results (Table 3) also revealed that advanced age ( $\geq 60$ years), poorly differentiated tumor, and LVSI were independent risk factors for deteriorative long-term survival in patients with stage IA2 cervical cancer.

\section{Discussion}

Radical hysterectomy and pelvic lymphadenectomy are the standard treatments for patients with stage IA2 cervical cancer. ${ }^{21}$ These procedures involve resection of the corpus of the uterus, cervix, parametria, cuff of the upper vagina, 
Table 2 Univariate Analyses of Prognostic Factors for DFS and OS in Patients with Stage IA2 Cervical Cancer

\begin{tabular}{|c|c|c|c|c|c|c|}
\hline & \multicolumn{3}{|c|}{$\mathbf{D F S}^{\mathbf{a}}$} & \multicolumn{3}{|c|}{ OS $^{b}$} \\
\hline & $H^{c}$ & $95 \% \mathrm{Cl}^{\mathrm{d}}$ & $\mathbf{P}$ & HR & $95 \% \mathrm{Cl}$ & $\boldsymbol{P}$ \\
\hline \multicolumn{7}{|l|}{ Age } \\
\hline$<60$ years & Reference & & & Reference & & \\
\hline$\geq 60$ years & 4.460 & $2.00 I-9.938$ & 0.000 & 4.928 & $1.560-15.562$ & 0.007 \\
\hline \multicolumn{7}{|l|}{ Marital status } \\
\hline Marriage & Reference & & & Reference & & \\
\hline Unmarried & 1.748 & $0.797-3.833$ & 0.163 & 1.901 & $0.613-5.896$ & 0.166 \\
\hline \multicolumn{7}{|l|}{ ASA $^{e}$ score } \\
\hline $\mathrm{I} / \mathrm{II}$ & Reference & & & Reference & & \\
\hline III & 3.673 & $1.532-8.809$ & 0.004 & 3.228 & $1.87 \mid-11.958$ & 0.009 \\
\hline \multicolumn{7}{|l|}{ Histology } \\
\hline $\operatorname{SCC}^{f}$ & Reference & & & Reference & & \\
\hline Adenocarcinoma & 0.914 & $0.337-2.479$ & 0.860 & 2.102 & $0.131-33.618$ & 0.599 \\
\hline $\mathrm{ASC}^{\mathrm{g}}$ & 1.167 & $0.342-3.981$ & 0.806 & 3.165 & $0.405-24.734$ & 0.272 \\
\hline \multicolumn{7}{|l|}{ Grade } \\
\hline $\mathrm{I} / \mathrm{II}$ & Reference & & & Reference & & \\
\hline III & 2.620 & $1.157-5.934$ & 0.021 & 4.681 & I.508-14.535 & 0.008 \\
\hline \multicolumn{7}{|l|}{ LVSI $^{h}$} \\
\hline No & Reference & & & Reference & & \\
\hline Yes & 2.338 & $0.976-5.603$ & 0.057 & 4.352 & I.378-9.745 & 0.012 \\
\hline \multicolumn{7}{|l|}{ Surgical approach } \\
\hline Open & Reference & & & Reference & & \\
\hline Laparoscopy & 1.325 & $0.745-2.3 \mid 2$ & 0.506 & 2.301 & $0.740-7.156$ & 0.250 \\
\hline \multicolumn{7}{|l|}{ Hysterectomy } \\
\hline $\mathrm{RH}^{\mathrm{i}}$ & Reference & & & Reference & & \\
\hline $\mathrm{SH}^{\mathrm{j}}$ & 1.298 & $0.537-3.137$ & 0.562 & 1.522 & $0.472-4.915$ & 0.482 \\
\hline \multicolumn{7}{|l|}{ Lymphadenectomy } \\
\hline Yes & Reference & & & Reference & & \\
\hline No & $1.06 \mathrm{I}$ & $0.364-3.092$ & 0.914 & 1.125 & $0.246-5.139$ & 0.879 \\
\hline \multicolumn{7}{|l|}{ Adjuvant $\mathbf{C T}^{\mathbf{k}}$} \\
\hline Yes & Reference & & & Reference & & \\
\hline No & 1.965 & $0.674-5.732$ & 0.216 & 2.117 & $0.463-9.690$ & 0.334 \\
\hline \multicolumn{7}{|l|}{ Adjuvant $\mathbf{R} \mathbf{T}^{\prime}$} \\
\hline Yes & Reference & & & Reference & & \\
\hline No & 2.744 & $0.82 I-9.173$ & 0.101 & 1.682 & $0.807-7.415$ & 0.193 \\
\hline
\end{tabular}

Notes: ${ }^{a}$ Disease-free survival; boverall survival; 'hazard ratio; ${ }^{d}$ confidence interval; ${ }^{e}$ American Society of Anesthesiology; ${ }^{f}$ squamous cell carcinomas; ${ }^{\mathrm{g}}$ adenosquamous

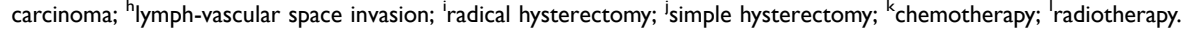

and bilateral pelvic lymph nodes. ${ }^{3}$ However, a growing number of studies have raised concerns about the overtreatment of radical hysterectomy for stage IA2 cervical cancer. ${ }^{5,22-24}$ All these concerns were raised based on the following reasons: relatively good prognosis for patients with stage IA2 cervical cancer, fairly low incidence of parametrial involvement in stage IA2 cervical cancer, and frequent intraoperative and postoperative complications associated with the resection of parametria that have significant adverse effects on the patient's quality of life.

In this study, we retrospectively studied the long-term survival outcomes of stage IA2 cervical cancer patients who underwent treatment and follow-up at our institute 
Table 3 Cox Proportional Hazards Regression Model for DFS and OS in Patients with Stage IA2 Cervical Cancer, with the Selection of Covariates Using Stepwise Forward Selection $(P<0.2)$

\begin{tabular}{|c|c|c|c|c|c|c|}
\hline & \multicolumn{3}{|c|}{ DFS $^{\mathbf{a}}$} & \multicolumn{3}{|c|}{$\operatorname{OS}^{b}$} \\
\hline & $a_{H} R^{c}$ & $95 \% \mathrm{Cl}^{\mathrm{d}}$ & $\boldsymbol{P}$ & aHR & $95 \% \mathrm{Cl}$ & $P$ \\
\hline \multicolumn{7}{|l|}{ Age } \\
\hline$<60$ years & Reference & & & Reference & & \\
\hline$\geq 60$ years & 3.792 & I.298-1।.074 & 0.015 & 5.525 & $|| .8|-25.84|$ & 0.030 \\
\hline \multicolumn{7}{|l|}{ Marital status } \\
\hline Marriage & Reference & & & Reference & & \\
\hline Unmarried & 2.502 & $0.89 \mid-5.724$ & 0.379 & 3.080 & $0.87 I-10.889$ & 0.081 \\
\hline \multicolumn{7}{|l|}{ ASA $^{e}$ score } \\
\hline I/II & Reference & & & Reference & & \\
\hline III & 1.987 & $0.614-6.428$ & 0.252 & I.34| & $0.239-7.523$ & 0.739 \\
\hline \multicolumn{7}{|l|}{ Grade } \\
\hline I/II & Reference & & & Reference & & \\
\hline III & 2.797 & I.204-6.498 & 0.017 & 4.591 & $1.414-14.904$ & 0.011 \\
\hline \multicolumn{7}{|l|}{ LVSI $^{f}$} \\
\hline No & Reference & & & Reference & & \\
\hline Yes & 2.262 & I.482-6.074 & 0.025 & 2.823 & $1.706-5.718$ & 0.017 \\
\hline \multicolumn{7}{|l|}{ Adjuvant $\mathbf{R T}^{\mathrm{g}}$} \\
\hline Yes & Reference & & & Reference & & \\
\hline No & 1.193 & $0.322-4.413$ & 0.792 & 2.557 & $0.569-11.494$ & 0.221 \\
\hline \multicolumn{7}{|l|}{ Hysterectomy } \\
\hline $\mathrm{RH}^{\mathrm{h}}$ & Reference & & & Reference & & \\
\hline $\mathrm{SH}^{\mathrm{i}}$ & 1.608 & $0.640-4.041$ & 0.312 & 1.122 & $0.319-3.493$ & 0.858 \\
\hline
\end{tabular}

Notes: ${ }^{a}$ Disease-free survival; ${ }^{b}$ overall survival; ${ }^{c}$ adjusted hazard ratio; ${ }^{\mathrm{d}}$ confidence interval; ${ }^{\mathrm{e}}$ American Society of Anesthesiology; ${ }^{\mathrm{f}}$ lymph-vascular space invasion;

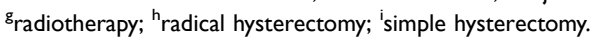

between January 2014 and December 2019. Using the Kaplan-Meier method and the Log rank test, we did not find a statistically significant difference in the 5-years OS rate and the 5-year DFS rate between the RH group and the SH group. Further Cox proportional hazards regression model also showed that the resection of parametrial did not affect the patient's survival; only the age, the grade of tumor differentiation, and the status of LVSI were independently related to the survival outcomes of patients with stage IA2 cervical cancer.

Previous studies that investigated the oncological safety of less radical hysterectomy for early-stage cervical cancer reported that the survival outcomes of patients who underwent simple hysterectomy seem favorable, and simple hysterectomy is safe and effective for early-stage cervical cancer, especially in stage IA2 cases. ${ }^{22,25-28}$ In 2019 , Sia et al used the data of the National Cancer Database to review the cases of women with stage IA2 cervical cancer from 2004 to 2015, they found that simple hysterectomy was performed in $44.6 \%$ of women with stage IA2 tumors during this period, and the rate of simple hysterectomy increased from $37.8 \%$ to $52.7 \%$ from 2004 to 2014 for stage IA2 cancers in the USA. ${ }^{25}$ Their study also reported that there was no association between surgical radicality and survival for women with stage IA2 tumors. ${ }^{25}$ However, their analyses did not include some important clinicopathologic variables, such as LVSI, postoperative adjuvant therapies, etc. ${ }^{25}$ The results of a recent systematic review and meta-analysis, which had 21 studies included, also showed that there was no significant difference in mortality between radical hysterectomy and simple hysterectomy for stage IA2 cervical cancer. ${ }^{22}$ It is worth noting that all studies included in this meta-analysis had a moderate-to-high risk of bias, and the level of evidence for this study was limited to III to IV. ${ }^{22}$

For cervical cancer, the most significant predictors that affect survival outcomes are disease stage, tumor volume, the status of regional lymph nodes, LVSI, and parametrial 
involvement. ${ }^{3,29}$ Also, more and more studies have challenged the perceived oncologic safety of minimally invasive surgery for early-stage cervical cancer. ${ }^{30-33}$ After controlling for potential confounding prognostic factors, our study identified advanced age at diagnosis, high-grade tumor, and LVSI as the independent risk factors for worse long-term survival outcomes in patients with stage IA2 cervical cancer; this result is consistent with that of other studies. ${ }^{34-36}$ However, our study found that a minimally invasive surgical approach was not associated with the deterioration of survival in stage IA2 cervical cancer. Previous studies on this topic did not specifically study the effects of laparoscopic surgery on the prognosis of only stage IA2 patients but treated patients of stage IA2, IB, and IIA1 as a whole cohort. Additional studies are needed to further the understanding of the effects of minimally invasive surgery on the survival of stage IA2 cases.

The main limitation of this study, like most existing studies on this topic, was its retrospective cohort study design. At present, no data from large-scale randomized controlled studies regarding this topic have been published yet. The Radical versus Simple Hysterectomy and Pelvic Node Dissection with Low-Risk Early-Stage Cervical Cancer (SHAPE) trial (NCT01658930) is an ongoing Phase III randomized controlled clinical study and the largest study on this subject so far. ${ }^{37}$ There will be 700 participants included in this study according to the protocol of this trial, and the primary outcome of this study is pelvic relapse-free survival. ${ }^{37}$ The result of this study will be instrumental in furthering the present knowledge of oncological safety and effectiveness of simple hysterectomy for stage IA2 cervical cancer.

\section{Conclusions}

For stage IA2 cervical cancer, simple hysterectomy was not associated with worse survival outcomes when compared with radical hysterectomy. A simple hysterectomy may be safe for patients with stage IA2 cervical cancer. Further studies are needed to testify against our findings.

\section{Abbreviations}

LVSI, lymphovascular space invasion; FIGO, the International Federation of Gynecology and Obstetrics; ASA, American Society of Anesthesiology; OS, overall survival; DFS, disease-free survival; HR, hazard ratio; CI, confidence interval.

\section{Ethics Approval}

The study was approved by the Ethics Committee of West China Second University Hospital, Sichuan University. This study was conducted in accordance with the Declaration of Helsinki. Due to the retrospective nature of this study and the fact that this study did not contain any identifiable private information, the requirement for informed consent was waived.

\section{Acknowledgment}

We thank Ivan Hen (University of Oxford) for critical proofreading of the manuscript.

\section{Author Contributions}

All authors made a significant contribution to the work reported, whether that is in the conception, study design, execution, acquisition of data, analysis and interpretation, or in all these areas; took part in drafting, revising or critically reviewing the article; gave final approval of the version to be published; have agreed on the journal to which the article has been submitted; and agree to be accountable for all aspects of the work.

\section{Funding}

The work of $\mathrm{Yu} \mathrm{Xu}$ was supported by the China Scholarship Council (grant number: 202006240331). The work of Ai Zheng was supported by grants from the Science and Technology Department of Sichuan Province (grant number: 2019YFS0417).

\section{Disclosure}

The authors report no conflicts of interest in this work.

\section{References}

1. Sung H, Ferlay J, Siegel RL, et al. Global cancer statistics 2020: GLOBOCAN estimates of incidence and mortality worldwide for 36 cancers in 185 countries. CA Cancer J Clin. 2021;71(3):209-249.

2. Small W Jr, Bacon MA, Bajaj A, et al. Cervical cancer: a global health crisis. Cancer. 2017;123(13):2404-2412. doi:10.1002/cncr.30667

3. Cohen PA, Jhingran A, Oaknin A, Denny L. Cervical cancer. Lancet (London, England). 2019;393(10167):169-182. doi:10.1016/S01406736(18)32470-X

4. Hull R, Mbele M, Makhafola T, et al. Cervical cancer in low and middle-income countries. Oncol Lett. 2020;20(3):2058-2074. doi:10. 3892/ol.2020.11754

5. Ramirez PT, Pareja R, Rendón GJ, Millan C, Frumovitz M, Schmeler KM. Management of low-risk early-stage cervical cancer: should conization, simple trachelectomy, or simple hysterectomy replace radical surgery as the new standard of care? Gynecol Oncol. 2014;132(1):254-259. doi:10.1016/j.ygyno.2013.09.004 
6. Frumovitz M, Sun CC, Schover LR, et al. Quality of life and sexual functioning in cervical cancer survivors. J Clin Oncol. 2005;23 (30):7428-7436. doi:10.1200/JCO.2004.00.3996

7. Alexander-Sefre F, Chee N, Spencer C, Menon U, Shepherd JH. Surgical morbidity associated with radical trachelectomy and radical hysterectomy. Gynecol Oncol. 2006;101(3):450-454. doi:10.1016/j. ygyno.2005.11.007

8. Liu P, Liang C, Lu A, et al. Risk factors and long-term impact of urologic complications during radical hysterectomy for cervical cancer in China, 2004-2016. Gynecol Oncol. 2020;158(2):294-302. doi:10.1016/j.ygyno.2020.05.029

9. Hwang JH, Kim BW, Jeong H, Kim H. Comparison of urologic complications between laparoscopic radical hysterectomy and abdominal radical hysterectomy: a nationwide study from the National Health Insurance. Gynecol Oncol. 2020;158(1):117-122. doi:10.1016/j.ygyno.2020.04.686

10. Wenzel HHB, Kruitwagen R, Nijman HW, et al. Short-term surgical complications after radical hysterectomy-a nationwide cohort study. Acta Obstet Gynecol Scand. 2020;99(7):925-932. doi:10.1111/ aogs. 13812

11. Sartori E, Fallo L, La Face B, Bianchi UA, Pecorelli S. Extended radical hysterectomy in early-stage carcinoma of the uterine cervix: tailoring the radicality. Int $J$ Gynecol Cancer. 1995;5(2):143-147. doi:10.1046/j.1525-1438.1995.05020143.x

12. Kashima K, Yahata T, Fujita K, Tanaka K. Analysis of the complications after radical hysterectomy for stage IB, IIA and IIB uterine cervical cancer patients. J Obstet Gynaecol Res. 2010;36(3):555-559. doi:10.1111/j.1447-0756.2010.01174.x

13. Likic IS, Kadija S, Ladjevic NG, et al. Analysis of urologic complications after radical hysterectomy. Am J Obstet Gynecol. 2008;199 (6):644.e641-643. doi:10.1016/j.ajog.2008.06.034

14. Stegeman M, Louwen M, van der Velden J, et al. The incidence of parametrial tumor involvement in select patients with early cervix cancer is too low to justify parametrectomy. Gynecol Oncol. 2007;105(2):475-480. doi:10.1016/j.ygyno.2007.01.016

15. Vranes B, Milenkovic S, Radojevic M, Soldatovic I, Kesic V. Risk of parametrial spread in small Stage I cervical carcinoma: pathology review of 223 cases with a tumor diameter of $20 \mathrm{~mm}$ or less. Int J Gynecol Cancer. 2016;26(2):416-421. doi:10.1097/IGC.0000000000000604

16. Jiamset I, Hanprasertpong J. Risk factors for parametrial involvement in early-stage cervical cancer and identification of patients suitable for less radical surgery. Oncol Res Treatment. 2016;39(7-8):432-438. doi:10.1159/000447335

17. Palaia I, Musella A, Bellati F, et al. Simple extrafascial trachelectomy and pelvic bilateral lymphadenectomy in early stage cervical cancer. Gynecol Oncol. 2012;126(1):78-81. doi:10.1016/j.ygyno.2012.04.004

18. Raju SK, Papadopoulos AJ, Montalto SA, et al. Fertility-sparing surgery for early cervical cancer-approach to less radical surgery. Int J Gynecol Cancer. 2012;22(2):311-317. doi:10.1097/IGC.0b013e3182370f51

19. Nguyen JMV, Covens A. Simple hysterectomy for early-stage cervical cancer: caution, but don't throw the baby out with the bathwater! Obstet Gynecol. 2019;134(6):1129-1131. doi:10.1097/AOG.00000 00000003589

20. World Medical Association. World Medical Association Declaration of Helsinki: ethical principles for medical research involving human subjects. JAMA. 2013;310(20):2191-2194.
21. Abu-Rustum NR, Yashar CM, Bean S, et al. NCCN guidelines insights: cervical cancer, Version 1.2020. J Natal Comp Cancer Net. 2020;18(6):660-666. doi:10.6004/jnccn.2020.0027

22. Wu J, Logue T, Kaplan SJ, et al. Less radical surgery for early-stage cervical cancer: a systematic review. Am J Obstet Gynecol. 2020;224:348-358.e5.

23. Al-Kalbani M, McVeigh G, Nagar H, McCluggage WG. Do FIGO stage IA and small $(\leq 2 \mathrm{~cm})$ IB1 cervical adenocarcinomas have a good prognosis and warrant less radical surgery? Int J Gynecol Cancer. 2012;22(2):291-295.

24. Bouchard-Fortier G, Reade CJ, Covens A. Non-radical surgery for small early-stage cervical cancer. Is it time? Gynecol Oncol. 2014;132(3):624-627. doi:10.1016/j.ygyno.2014.01.037

25. Sia TY, Chen L, Melamed A, et al. Trends in use and effect on survival of simple hysterectomy for early-stage cervical cancer. Obstet Gynecol. 2019;134(6):1132-1143. doi:10.1097/AOG.0000000000003523

26. Marana HR, de Andrade JM, Matthes AC, Spina LA, Carrara HH, Bighetti S. Microinvasive carcinoma of the cervix. Analysis of prognostic factors. Eur J Gynaecol Oncol. 2001;22(1):64-66.

27. Chen L, Zhang WN, Zhang SM, Gao Y, Zhang TH, Zhang P. Class I hysterectomy in stage IA2-IB1 cervical cancer. Videosurg Other Miniinvasive Tech. 2018;13(4):494-500. doi:10.5114/wiitm.2018.76832

28. Smith HO, Qualls CR, Romero AA, et al. Is there a difference in survival for IA1 and IA2 adenocarcinoma of the uterine cervix? Gynecol Oncol. 2002;85(2):229-241.

29. Liontos M, Kyriazoglou A, Dimitriadis I, Dimopoulos MA, Bamias A. Systemic therapy in cervical cancer: 30 years in review. Crit Rev Oncol Hematol. 2019;137:9-17. doi:10.1016/j.critrevonc.2019.02.009

30. Ramirez PT, Frumovitz M, Pareja R, et al. Minimally invasive versus abdominal radical hysterectomy for cervical cancer. $N$ Engl J Med. 2018;379(20):1895-1904. doi:10.1056/NEJMoa1806395

31. Melamed A, Margul DJ, Chen L, et al. Survival after minimally invasive radical hysterectomy for early-stage cervical cancer. $N$ Engl J Med. 2018;379(20):1905-1914. doi:10.1056/NEJMoa1804923

32. Nitecki R, Ramirez PT, Frumovitz M, et al. Survival after minimally invasive vs open radical hysterectomy for early-stage cervical cancer: a systematic review and meta-analysis. JAMA Oncol. 2020;6 (7):1019-1027. doi:10.1001/jamaoncol.2020.1694

33. Smith AJB, Jones TN, Miao D, Fader AN. Minimally invasive radical hysterectomy for cervical cancer: a systematic review and meta-analysis. J Minim Invasive Gynecol. 2021;28(3):544-555. e547. doi:10.1016/j.jmig.2020.12.023

34. Atasii T, Aksu MF, Cetinkaya MB. Prognostic factors that affect survival after the treatment of early stage cervical carcinoma. Int Surg. 2000;85(2):147-151.

35. Kenter GG, Ansink AC, Heintz AP, Delemarre J, Aartsen EJ, Hart AA. Low stage invasive carcinoma of the uterine cervix stage I-IIA morphological prognostic factors. Eur J Surg Oncol. 1988;14(2):187-192.

36. Burghardt E, Baltzer J, Tulusan AH, Haas J. Results of surgical treatment of 1028 cervical cancers studied with volumetry. Cancer. 1992;70(3):648-655. doi:10.1002/1097-0142(19920801)70:3<648:: AID-CNCR2820700318>3.0.CO;2-R

37. Plante M. Radical versus simple hysterectomy and pelvic node dissection with low-risk early stage cervical cancer (SHAPE). Available from: https://clinicaltrials.gov/ct2/show/NCT01658930. Accessed March 10, 2021. 


\section{Publish your work in this journal}

Cancer Management and Research is an international, peer-reviewed The manuscript management system is completely online and includes open access journal focusing on cancer research and the optimal use of preventative and integrated treatment interventions to achieve improved a very quick and fair peer-review system, which is all easy to use. Visit http://www.dovepress.com/testimonials.php to read real quotes outcomes, enhanced survival and quality of life for the cancer patient. from published authors.

Submit your manuscript here: https://www.dovepress.com/cancer-management-and-research-journal 